\section{Actividad antibacteriana in vitro del propilenglicol ozonizado (Endozone $®$ ) sobre Enterococcus faecalis en conductos radiculares de dientes de bovino}

\author{
In vitro antibacterial activity of ozonized \\ propyleneglycol (Endozone®) on \\ Enterococcus faecalis in root canals of \\ bovine teeth
}

\section{Resumen}

Objetivo: Determinar la actividad antibacteriana in vitro del propilenglicol ozonizado (Endozone ${ }^{\circledR}$ ) y ultrasonido sobre Enterococcus faecalis (E. faecalis) en conductos radiculares de dientes de bovino. Métodos: El estudio fue de tipo experimental y se realizó en el laboratorio de microbiología de la Facultad de Biología de la Universidad Nacional del Altiplano-Puno. Las muestras fueron sembradas en agar bilis esculina, se contaminó dientes de bovino con $E$. faecalis a los cuales se les aplicó Endozone ${ }^{\circledR}$ y ultrasonido en distintos tiempos de acción luego de este procedimiento se realizó el recuento de desarrollo de colonias para cada diente mediante la técnica de observación directa estructurada. Resultados: El promedio de la actividad antibacteriana del Endozone ${ }^{\circledR}$ sobre E. faecalis fue de $92 \%$, el promedio de la actividad antibacteriana del Endozone ${ }^{\circledR}$ aplicado con ultrasonido por 10 segundos fue de 94,63\%, aplicado por 20 segundos fue $95,01 \%$ y aplicado por 30 segundos fue $96,74 \%$, observamos que la actividad antibacteriana es directamente proporcional al tiempo de aplicación, la prueba estadística de Kruskal-Wallis indicó diferencias significativas entre los diferentes tiempos de aplicación. Conclusiones: El Endozone $^{\circledast}$ con aplicación de ultrasonido, tuvo mayor actividad antibacteriana que solo Endozone ${ }^{\circledast}$ sobre E. faecalis. La aplicación de Endozone ${ }^{\circledast}$ y ultrasonido por 30 segundos mostró mayor actividad antibacteriana.

Palabras clave: Antibacterianos; Enterococcus faecalis; Ozono; Propilenglicol.

\section{Artículo Original}

Andrea Katioska Alata-Marcavillaca ${ }^{1, a}$,

Oliver Luis Reyes-Jiménez 2,a, Gisell Mariela

Ramos-Quenaya ${ }^{2, a, b}$, Hernán Freddy

Ortega-Cruz ${ }^{1, a, c}$

${ }^{1}$ Facultad de Odontología. Universidad Nacional del Altiplano. Puno, Perú.

${ }^{2}$ Universidad Nacional Mayor de San Marcos,

Facultad de Odontología. Lima, Perú.

${ }^{\text {a }}$ Cirujano Dentista

${ }^{\mathrm{b}}$ Especialista en Carielogía y Endodoncia

${ }^{c}$ Magister en Endodoncia

\section{Correspondencia:}

Oliver Luis Reyes-Jiménez

Correo electrónico: obber4@hotmail.com

Jr. Huancané 859 Juliaca, Puno, Perú.

\section{Coautores:}

Andrea Katioska Alata-Marcavillaca

andreakati16@gmail.com

Gisell Mariela Ramos-Quenaya

gisellmariel@hotmail.com

Hernán Freddy Ortega-Cruz

hfortegac@hotmail.com

Conflicto de intereses: Los autores declaran no tener conflictos de interés.

Fuente de financiamiento: Autofinanciado

Fecha de recepción: 10/08/17

Fecha de aceptación: 27/03/18

( L Los autores. Este artículo es publicado por la revista Odontología Sanmarquina de la Facultad de Odontología, Universidad Nacional Mayor de San Marcos. Este es un artículo de acceso abierto, distribuido bajo los términos de la licencia Creative Commons Atribucion - No Comercia_Compartir Igual 4.0 Internacional. (http://creativecommons.org/licenses/by-nc-sa/4.0/) que permite el uso no comercial, distribución y reproducción en cualquier medio, siempre que la obra original sea debidamente citada. 
seconds was $94,63 \%$, applied for 20 seconds was $95,01 \%$ and applied for 30 seconds was $96,74 \%$, we observed that the antibacterial activity is directly proportional to the time of application, the statistical test of Kruskall-Wallis indicated that there were significant differences between the different times of application. Conclusions: Endozone ${ }^{\circledR}$ with ultrasound application had a higher antibacterial effect than Endozone ${ }^{\circledR}$ on E. faecalis. The application of Endozone ${ }^{\circledR}$ and ultrasound for 30 seconds showed greater antibacterial activity.

Keywords: Anti-bacterial agents; Enterococcus faecalis; Ozone; Propylene glycol.

\section{Introducción}

Actualmente, resulta cada vez mayor la incorporación de la ozonoterapia en el tratamiento odontológico, lo cual ocurre por la tendencia existente en salud dirigida hacia las terapias naturales, con esta perspectiva resulta importante que el amplio número de métodos, técnicas y procedimientos que abarca la ozonoterapia, alcancen cada vez mayor desarrollo en nuestro medio y ocupen un lugar significativo en el arsenal terapéutico para nuestros pacientes en Odontología ${ }^{1-4}$. El ozono, forma alotrópica del oxígeno, generado artificialmente en un equipo de alto voltaje a partir del oxígeno medicinal, es un gas altamente tóxico e inestable lo que hace que sea difícil el manejo en la práctica clínica odontológica, una alternativa sugerida es usar líquidos o aceites como vehículo para el gas 5,6. La amplia disponibilidad de sustancias ozonizadas hace de este un agente antimicrobiano competitivo ya que la actividad antibacteriana de estos productos frente a bacterias frecuentemente implicadas en infecciones bucales son reportadas en estudios a nivel mundial, estos resultados deben impulsar la creación de nuevos estudios y ensayos clínicos para comparar compuestos ozonizados con otros agentes antimicrobianos $7-9$.

Ortega et al. evaluaron in vitro la actividad antibacteriana del ozono unido a vehículos y medicamentos de acción prolongada, evaluando la capacidad de asociación de la actividad antimicrobiana del ozono en diversos vehículos como aceite de oliva, aceite de girasol, propilenglicol y medicamentos de acción prolongada como propilenglicol con hidróxido de calcio y este con paramonoclorofenol alcanforado, con la intención de encontrar un medicamento de acción prolongada de gran poder germicida y de baja o ninguna toxicidad para los tejidos paradentarios, concluyendo que el propilenglicol mostró la mejor capacidad de asociación al ozono, seguida del propilenglicol con hidróxido de calcio, aceite de girasol y aceite de oliva respectivamente ${ }^{10}$.

El propilenglicol ozonizado podría ser usado como agente antimicrobiano en los fracasos de tratamiento de conductos ocasionados por la subsistencia de microorganismos patógenos, siendo el Enterococcus faecalis ( $E$. faecalis) el que predomina, además de presentar una alta resistencia bacteriana ${ }^{11}$. Parí evaluó in vitro la actividad antimicrobiana del propilenglicol ozonizado aplicado en conductos radiculares de dientes contaminados con E. faecalis, donde utilizó 40 dientes humanos uniradiculares, después de ser preparados, fueron contaminados con $E$. faecalis, luego se aplicó $0,5 \mu \mathrm{L}$ de propilengli- col ozonizado, realizando un control bacteriológico por presencia de colonias de esta bacteria. Concluyó que el propilenglicol ozonizado sí tiene actividad antimicrobiana estadísticamente significativo, sobre E. faecalis ${ }^{12}$. Podemos potenciar la actividad antimicrobiana de las diferentes sustancias antimicrobianas usadas en endodoncia con el uso del ultrasonido que se basa en los distintos fenómenos que se producen durante la aplicación de éste dentro del conducto radicular, estos fenómenos de oscilación, cavitación, microcorriente acústica y generación de calor, van a producir efectos sobre la estructura dentaria, especialmente sobre la dentina y la capa de barrillo dentinario, así como la potenciación de efectos antimicrobianos al utilizarse en combinación con soluciones irrigantes ${ }^{13}$.

El objetivo del estudio fue determinar la actividad antibacteriana in vitro del propilenglicol ozonizado (Endozone $^{\circledast}$ ) y ultrasonido sobre E. faecalis, bacteria asociada a los fracasos endodonticos.

\section{Métodos}

Para la realización de este estudio se aislaron cepas bacterianas de dientes con absceso periodontal, la cepa de referencia que se usó para la estandarización del estudio fue Enterococcus faecalis ATCC 19433. Las muestras fueron sembradas en agar bilis esculina para ser cultivadas por 24 horas a $37^{\circ} \mathrm{C}$, donde se identificó colonias de $E$. faecalis en base a la lectura morfológica de su colonia y la adherencia al agar; para la identificación definitiva se desarrolló la prueba bioquímica de Bilis Esculina, donde se agregó dos gotas de citrato férrico amoniacal, donde se observó ennegrecimiento del medio, lo que nos confirmó la identificación de E. faecalis (Figura 1).

Se utilizaron 40 incisivos inferiores de bovino recientemente extraídos de ganado sacrificado para consumo humano, los criterios de inclusión de la muestra fueron dientes de bovino anteriores uniradiculares, dientes de bovino en buen estado, sin caries y los criterios de exclusión fueron dientes de bovino con alteraciones de morfología. Se eliminaron los restos orgánicos del conducto radicular de cada diente con limas endodónticas e hipoclorito de sodio para luego ser esterilizados en autoclave en $126^{\circ} \mathrm{C}, 2.0 \mathrm{~atm}$ por 10 minutos. Se formaron cuatro grupos de diez dientes cada uno, en los cuales se realizó la contaminación de todos los dientes con cepas de E. faecalis y se dejó la muestra en la incubadora por 7 días a $37^{\circ} \mathrm{C}$ en sus respectivos tubos de ensayo en un ambiente de anaerobiosis, después de 7 días se procedió a realizar la instrumentación biomecánica empleando 
el sistema rotatorio Mtwo, modelo VDW.SILVER de procedencia alemana, irrigando con Endozone ${ }^{\circledR}$. En el primer grupo se procedió a evaluar la actividad antibacteriana de la instrumentación rotatoria y el Endozone ${ }^{\circledR}$; en el segundo grupo, luego de la instrumentación rotatoria e irrigación con Endozone ${ }^{\circledR}$, se aplicó nuevamente Endozone $^{\circledR}$ y ultrasonido por 10 segundos; en el tercer grupo se aplicó Endozone ${ }^{\circledR}$ y ultrasonido por 20 segundos; en el cuarto grupo se aplicó Endozone ${ }^{\circledR}$ y ultrasonido por 30 segundos, el equipo de ultrasonido fue usado a $6000 \mathrm{~Hz}$, el modelo utilizado fue woodpecker UDS - B de procedencia china.

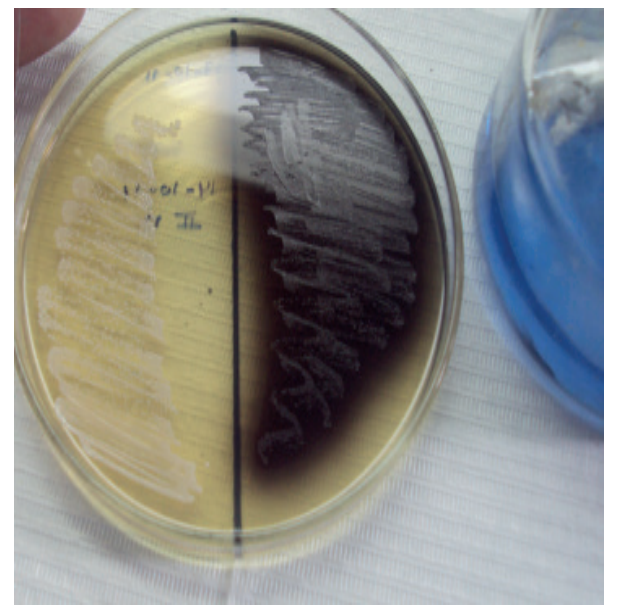

Figura 1. Identificación de E. faecalis, la hidrólisis de la esculina libera glucosa y esculetina, la esculetina en presencia de $\mathrm{Fe}^{3}$ forma la coloración negra cuando la prueba es positiva para la identificación de E. faecalis.

El inóculo del $E$. faecalis fue preparado en tubos de ensayo, suspendiendo las colonias puras aisladas en $0,5 \mathrm{~mL}$ de suero fisiológico hasta obtener una turbidez de 0,5 según el método de Mc Farland, que corresponde a una concentración de $1,5 \times 10^{8} \mathrm{UFC} / \mathrm{mL}$ de E. faecalis, utilizando una jeringa de tuberculina se inoculó $0,5 \mathrm{~mL}$ de suspensión bacteriana en agar bilis esculina y se encubó a $37^{\circ} \mathrm{C}$ por 48 horas, el método de anaerobiosis usado para mantener un ambiente libre de oxígeno durante el procesamiento de los especímenes fue la técnica de la jarra anaeróbica, en el cual el principio básico de ésta es la remoción del oxígeno presente en la cámara, lo cual ocurre por la reacción con el hidrógeno producido en la presencia de un catalizador.

Luego de este procedimiento, se realizó al recuento de colonias, el cual se efectuó mediante la técnica de observación directa estructurada, registrando, codificando y clasificando los datos observados en una ficha de recolección de datos ${ }^{14-16}$.

\section{Resultados}

En los cuatro grupos experimentales se determinó el número de microorganismos en relación a las colonias que se forman por cada diente de bovino contaminado, del cual se halló el promedio en cada grupo, los cuales fueron $4,84 \times 10^{3}$ en el primer grupo, $4,79 \times 10^{3}$ en el segundo grupo, 4,82 x $10^{3}$ en el tercer grupo y 4,83 $\mathrm{x} 10^{3}$ en el cuarto grupo. En la Tabla 1 se muestra la actividad antibacteriana del Endozone ${ }^{\circledR}$ y ultrasonido sobre $E$. faecalis siendo el mayor promedio de actividad antibacteriana de $96,74 \%$ para el grupo que se aplicó Endozone $^{\circledR}$ y ultrasonido por 30 segundos y el menor promedio de actividad antibacteriana de $92 \%$ fue para el grupo que se aplicó solo Endozone ${ }^{\circledR}$, se puede apreciar que la actividad antibacteriana sobre $E$. faecalis es directamente proporcional al tiempo de aplicación, el análisis estadístico mediante la prueba de Kruskall-Wallis indicó

Tabla 1. Actividad antibacteriana in vitro del Endozone ${ }^{\circledR}$ y ultrasonido sobre $E$. faecalis en conducto radicular de dientes de bovino.

\begin{tabular}{lcccc}
\hline & $\begin{array}{c}\text { Promedio de crecimien- } \\
\text { to } \\
\text { bacteriano en } \\
\text { UFC/mL } \\
\text { pre tratamiento }\end{array}$ & $\begin{array}{c}\text { Promedio de crecimien- } \\
\text { to } \\
\text { bacteriano en UFC/mL } \\
\text { post tratamiento }\end{array}$ & $\begin{array}{c}\text { Promedio } \\
\text { crecimiento } \\
\text { bacteriano } \\
\text { post tratamiento (\%) }\end{array}$ & $\begin{array}{c}\text { Promedio de } \\
\text { actividad } \\
\text { antibacteriana } \\
\text { post tratamiento (\%) }\end{array}$ \\
GRUPO & $4,84 \times 10^{3}$ & $0,812 \times 10^{3}$ & 8,00 & 92,00 \\
\hline $\begin{array}{l}\text { Endozone } \\
\text { Endozone y Ultrasonido } \\
\text { por 10 s }\end{array}$ & $4,79 \times 10^{3}$ & $0,545 \times 10^{3}$ & 5,37 & 94,63 \\
$\begin{array}{l}\text { Endozone y Ultrasonido } \\
\text { por 20 s }\end{array}$ & $4,82 \times 10^{3}$ & $0,507 \times 10^{3}$ & 4,99 & 95,01 \\
$\begin{array}{l}\text { Endozone y Ultrasonido } \\
\text { por 30 s }\end{array}$ & $4,83 \times 10^{3}$ & $0,331 \times 10^{3}$ & 3,26 & 96,74 \\
\hline
\end{tabular}

UFC/mL: Unidades formadoras de colonias por mililitro. 
que sí existe diferencias significativas $(p<0,05)$ entre los diferentes tiempos de aplicación.

\section{Discusión}

La limpieza biomecánica y la conformación de los conductos radiculares junto con la medicación intraconducto son esenciales para la eliminación de la microflora endodóntica presentes en el sistema de conductos radiculares contaminados para así aumentar las probabilidades de éxito en la terapia de conductos, se ha demostrado que el $E$. faecalis es el principal responsable de la persistencia de la infección periapical y/o fracaso endodóntico. Estudios que emplean irrigación ultrasónica presentan conductos radiculares significativamente más limpios que los preparados convencionalmente, la literatura endodóntica muestra que es más ventajoso aplicar el ultrasonido después de la preparación completa del conducto ${ }^{12,13}$.

El Endozone ${ }^{\oplus}$, que tiene un poder antibacteriano, ha sido aplicado en diversos estudios como medicamento intraconducto, por ser bacterecida, fungicida y virucida. Una de sus ventajas en endodoncia es que disminuye la posibilidad de coloración de la pieza por la oxidación del material orgánico remanente en los conductillos dentinarios, promueve la disminución de microorganismos en la zona ápico-coronal, además de poseer propiedades de inducción a la reparación ósea y propiedades desinflamaotrias ${ }^{10,12,17}$. En el estudio se confirmó la actividad antibacteriana del Endozone ${ }^{\circledast}$ como irrigante intraconducto en los diferentes tiempos de aplicación evaluados. Se pudo observar que la aplicación del Endozone ${ }^{\circledR}$ y ultrasonido tiene actividad antibacteriana sobre E. faecalis, estos resultados son similares a los resultados que presento Vieira ${ }^{17}$ que en su estudio evaluó la actividad antimicrobiano de los medicamentos en los canales de raíces dentales contaminados con E. faecalis de dientes humanos unirradiculares, en el que demostró que el propilenglicol ozonizado y el hidróxido de calcio con paramonofenol alcaforado estadísticamente redujeron el número de bacterias en comparación con el grupo control positivo, Pari ${ }^{12}$, en su estudio, determinó la actividad antimicrobiana del propilenglicol ozonizado aplicado en los conductos de dientes unirradiculares infectados con E. faecalis, concluyendo que el propilenglicol ozonizado tiene actividad antimicrobiana estadísticamente significativa, sobre $E$. faecalis, sin embargo, los estudios realizados han aplicado el ozono como medicación intraconducto, a diferencia del estudio realizado en el que, el ozono ha sido aplicado como irrigante final, logrando en menos tiempo de acción mayor eficacia antibacteriana, lo cual hace la diferencia en el porcentaje de los resultados ya que los irrigantes más usados tienen un tiempo mínimo de aplicación para su éxito, esto sugiere que deben realizarse nuevos estudios donde se aplique mayores tiempos de aplicación hasta lograr el 100\% de efecto antibacteriano. Por lo expuesto, la terapia con soluciones ozonizadas es una prometedora opción como coadyuvante en el tratamiento endodóntico ${ }^{18-20}$.
El presente estudio demostró que el Endozone ${ }^{\circledast}$ aplicado con ultrasonido tiene actividad antibacteriana sobre el crecimiento del $E$. faecalis y que el tiempo de aplicación del Endozone ${ }^{\oplus}$ guarda relación proporcional directa con la actividad antibacteriana; puede afirmarse la eficiencia del Endozone ${ }^{\oplus}$, ya que alcanzó el 96,74\% de actividad antibacteriana, sin embargo, aún no alcanza el $100 \%$ de actividad antibacteriana sobre el E. faecalis, por lo que se recomienda estudios in vivo y ensayos clínicos aleatorizados evaluando el grado de infección de conducto radicular y la eficacia clínica del Endozone ${ }^{\circledR}$.

\section{Referencias Bibliográficas}

1. Rodriguez J, Wolfsohn B, Mier M. Eficacia del OLEO$\mathrm{ZON}^{\circledR}$ oral como medicamento intraconducto en el tratamiento endodóntico. Rev Espańola de Ozonoterapia. 2017;7(1):29-38.

2. Travagli VI, Zanardi P, Bernini S, Nepi L, Tenori V. Effects of ozone blood treatment on the metabolite profile of human blood. Int J Toxicol. 2010;29(16):51-74.

3. Moureu S, Violleau F, Ali Haimoud-Lekhal D, Calmon A. Ozonation of sunflower oils: impact of experimental conditions on the composition and the antibacterial activity of ozonized oils. Chem Phys Lipids. 2015;18(6):79-85.

4. Travagli V, Zanardi I, Valacchi G, Bocci V. Ozone and ozonated oils in skin diseases: a review. Mediators Inflamm. 2010;61(4):18-24.

5. Dhingra K, Vandana KL. Management of gingival inflammation in orthodontic patients with ozonated water irrigation-a pilot study.Int J Dent Hyg. 2011;9(4):296-302.

6. Martínez-Sánchez L, Perez-Davison G, Rosemeres-Horwat D. Las aplicaciones médicas de los aceites ozonizados, actualización. Rev Española de Ozonoterapia. 2012;2(1):121-139.

7. Huth KC, Jakob FM, Saugel B, Cappello C, Paschos E, Hollweck R, et al. Effect of ozone on oral cells compared with established antimicrobials. Euro J Oral Sci. 2006;114(5):435-40.

8. Sechi LA, Lezcano I, Nunez N, Espim M, Duprè I, Pinna $A$, et al. Antibacterial activity of ozonized sunflower oil (Oleozon). J Appl Microbiol. 2001;90(2):279-84.

9. Guinesi AS, Andolfatto C, Bonetti Filho I, Cardoso AA, Passaretti Filho J, Farac RV. Ozonized oils: a qualitative and quantitative analysis. Braz Dent J. 2011;22(1):3740.

10. Ortega HF, Bonetti I, López BP. Evaluación in vitro de la asociación del efecto antimicrobiano del ozono unido a vehículos y medicamentos de acción prolongada. Acta Odontol Venez. 2008;46(2):1-9.

11. Frough-Reyhani M, Ghasemi N, Soroush-Barhaghi M, Amini M, Gholizadeh Y. Antimicrobial efficacy of different concentration of sodium hypochlorite on the biofilm of Enterococcus faecalis at different stages of development. J Clin Exp Dent. 2016;8(5):480-484.

12. Parí I. Estudio In vitro del efecto antimicrobiano producido por el propilenglicol ozonizado sobre Enterococcus faecalis en conductos radiculares y controlado en diferentes tiempos. [Tesis para optar el título de Cirujano 
Dentista]. [Puno]: Facultad de Odontología, Universidad Nacional del Altiplano; 2008.

13. Neuhaus KW, Liebi M, Stauffacher S, Eick S, Lussi A. Antibacterial Efficacy of a New Sonic Irrigation Device for Root Canal Disinfection. J Endod. 2016;42(12):17991803.

14. Guerci A. Laboratorio Métodos de Análisis Clínicos y su interpretación 4ta ed. Argentina: El Ateneo;1988. p. 402-416.

15. Nogales CG, Ferrari PH, Kantorovich EO, Lage-Marques JL. Ozone therapy inmedicine and Dentistry. J Contemp Dent Pract. 2008;9(4):75-84.

16. Sega A, Zanardi I, Chiasserini L, Gabbrielli A, Bocci V, Travagli V. Properties of sesame oil by detailed $1 \mathrm{H}$ and 13C NMR assignments before and after ozonation and their correlation with iodine value, peroxide value, and viscosity measurements. Chem Phys Lipids. 2010;163(2):148-56.
17. Vieria R. Avaliação do efeito bactericida do ozônio associado ao propilenoglicol em canais radiculares contaminados com enterococcus faecalis em diferentes períodos de tempo de armazenagem. [Tesis Maestral]. [Araraquara]: Facultade de Odontologia Universidade Estadual Paulista; 2010.108 p.

18. Hao K, Li Y, Feng J, Zhang W, Zhang Y, Ma N, et al. Ozone promotes regeneration by regulating the inflammatory response in zebrafish. Int Immunopharmacol. 2015;28(1):369-75.

19. Makeeva I, Turkina A, Margaryan E, Paramonov Y, Polyakova M. Assessment of antibacterial efficacy of ozone therapy in treatment of caries at the white spot stage. Stomatologiia Mosk. 2017;96(4):7-10.

20. Noites R, Pina-Vaz C, Rocha R, Carvalho M, Gonçalves A, Pina-Vaz I. Synergistic antimicrobial action of chlorhexidine and ozone in endodontic treatment. Biomed Res Int. 2014;20(14):1-7. 
